\title{
Does the octave illusion evoke the interaural tempo illusion?
}

\author{
SIMONE AKERBOOM, GERT ten HOOPEN, and ARJEN van der KNOOP \\ University of Leiden, Leiden, The Netherlands
}

\begin{abstract}
Many observers experience an auditory illusion when presented with a repeating dichotic chord (consisting of a $400-\mathrm{Hz}$ and an $800-\mathrm{Hz}$ tone) that alternates between the ears. Listeners state that they hear a sequence of single tones, alternating between a low and a high pitch and at the same time alternating between the ears. This is called the octave illusion (Deutsch, 1974, 1980). The aim of the present study was to measure objectively the subjective angle over which the illusory single tone alternates. Informal listening in our laboratory suggested that the subjective tones were not fully alternating over $180^{\circ}$. In order to measure the precise angular separation in the octave illusion, we made use of another illusion. If sounds are alternated between locations, the time intervals between the sounds appear to be longer, and when the angle of alternation becomes larger, the rate of the sequence appears to be slower (interaural tempo illusion). By means of a reaction-time technique, it is possible to infer the angle of alternation from the apparent rate. Listeners who indeed perceived the octave illusion had to perform the reaction-time task with the dichotic tone sequences (giving rise to the octave illusion) and several types of controltone sequences. The reaction times showed that the time intervals between the subjectively alternating tones in the octave illusion were not longer than the intervals between nonalternating tones. Hence, we can conclude that the output of the "what-where" mechanism is not operated on by the interaural tempo processor.
\end{abstract}

When listeners are presented with two or more simultaneous speech messages, they may be able to hear one message in the foreground and the other(s) in the background. This capability is dependent on several factors which are rather well documented by the large number of studies on selective auditory attention (see Moray, 1969 , and Broadbent, 1971, for surveys). In the last decade, interest in auditory figure-ground articulation has revived with regard to nonspeech signals, such as tone sequences and music (see Bregman, 1978; Deutsch, 1982). A powerful perceptual mechanism that invokes figure-ground separation between speech signals is based on the difference in location between the sound sources. ${ }^{1}$ In most studies, the difference in location is simulated by dichotically presenting two speech streams. However, when two tone sequences are presented in a dichotic fashion, there are cases in which a separation according to ears is overruled by an organization according to frequency. An example is the well-known scale illusion (Deutsch, 1975a, 1975b).

\section{The Octave Illusion}

An even more complex interplay between location and frequency may be encountered when analyzing the octave

This study was supported by Grant 15-26-14 of the Netherlands Organization for the Advancement of Pure Research (ZWO). Thanks are due to Loes Nas for her assistance with the translation into English. Requests for reprints should be sent to Gert ten Hoopen. Unit of Experimental Psychology, Hooigracht 15, $2312 \mathrm{KM}$ Leiden, The Netherlands. illusion (Deutsch, 1974, 1980; Deutsch \& Roll, 1976; Zwicker, 1984). The stimulus consists of a dichotic chord of 250 -msec tones in octave relation $(400-800 \mathrm{~Hz})$ that is presented repetitively without silent gaps. At each consecutive presentation, the chord is alternated between ears. When the left ear receives, for instance, $400,800,400$, $800 \mathrm{~Hz}$, and so on, the right ear receives $800,400,800$, $400 \mathrm{~Hz}$, and so on. Although a two-tone chord was presented, most of the time listeners perceived a single tone. This tone alternated between the ears, and as it shifted position, its pitch alternated. This illusion did not change when the earphones were reversed. Furthermore, right-handed subjects strongly tended to hear the high tones in the right ear and the low tones in the left ear. Deutsch proposed that the illusion was the result of an intricate cooperation of two different selection mechanisms, one for determining the pitch and the other for determining the location. The frequency arriving at the dominant ear is selected while at the same time the frequency arriving at the nondominant ear is suppressed. The percept, no matter whether a high or low tone, is localized in the ear that receives the higher frequency.

Although informal listening at our laboratory showed that the subjective single tone shifts between a low and a high pitch, the concurrent subjective alternation between positions in the head appeared to be less pronounced than an objective left-right alternation. A crude, informal estimate of the subjective angular separation was $120^{\circ}$ to $150^{\circ}$. Whereas the low tones indeed appeared to be lateralized in the left ear, the high tones appeared not to be fully lateralized toward the right ear. Of course, this in- 
formal observation required formal investigation, and for this reason the present study was undertaken.

\section{The Interaural Tempo Illusion}

Ten Hoopen, Vos, and Dispa (1982) established that in order to detect the end of an interaural sequence (alternating over $180^{\circ}$ ), their listeners needed 24 msec more than they needed to detect the end of a monaural sequence. This difference of $24 \mathrm{msec}$ reflects the difference in the subjective time intervals between the percepts of the interaural and monaural sounds. We coined the term "perceptual onset asynchrony" (POA), which is the mental time representation of the stimulus onset asynchrony (SOA). Thus, although the interaural and monaural SOAs were equal, their POAs differed by $24 \mathrm{msec}$. Moreover, this difference was invariant with the value of SOA $(125-250 \mathrm{msec})$. We shall call this subjective time dilation between ear-alternating sounds the "interaural tempo illusion." A subsequent study demonstrated that this illusion holds for a much larger SOA range, namely 40-2,130 msec (Akerboom, ten Hoopen, Olierook, \& van der Schaaf, 1983).

\section{Stop-RT as a Measure of Angular Separation}

Akerboom et al. (1983) also posed the question as to what extent the time dilation is affected by the angular separation between the location-alternating sounds. Psychophysical data from Axelrod and Powazek (1972) pointed out that the apparent rate of a sequence becomes slower with increasing angular separation between the alternating sounds. Hence, Akerboom et al. (1983) applied the "stop-reaction time" (stop-RT) technique to locationalternating sequences and systematically varied the angular separation. We shall summarize this technique here (for a complete discussion see ten Hoopen, Vos, \& Dispa, 1982).

Listeners are required to respond as fast as possible to the unpredictable end of a sound sequence. The stop-RT comprises two durations. The first duration is the POA between the sounds. This is the criterion time that the subjects set for themselves after each sound; if no further sound arrives during that time, they initiate their response, and the amount of time this takes is the second duration. If it is assumed that response-initiation time is invariant with the presentation mode (interaural vs. monaural), then one can interpret differences between stop-RTs as differences between POAs. The angular separation between the two sound-emitting loudspeakers in the Akerboom et al. (1983) study could be $0^{\circ}, 30^{\circ}, 60^{\circ}, 90^{\circ}, 120^{\circ}, 150^{\circ}$, or $180^{\circ}$. It was found that the POA difference between location-alternating and nonalternating sequences increased linearly with increasing angular separation (see Figure 1). Given this linear relation, we can translate any stop-RT difference, that is, POA difference, into the corresponding angular separation.

The only problem, however, is that this relation has been established with a localization paradigm (loudspeakers) instead of a lateralization paradigm (head-

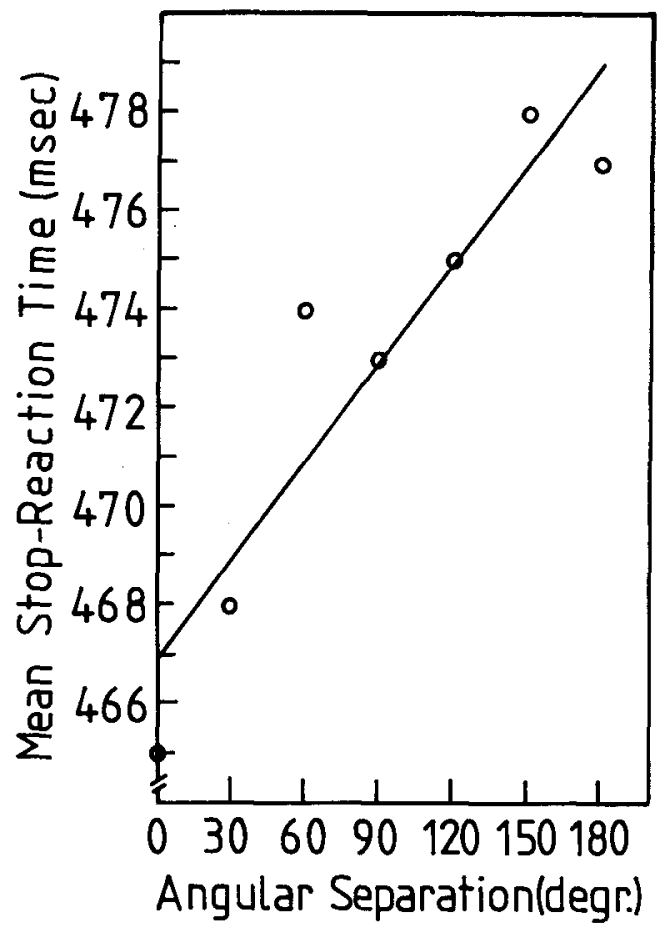

Figure 1. Mean stop-reaction times dependent on angular separation between the ear-alternating noise bursts. The linear regression line is inserted [stop-RT $=467+.07$ angular separation $\left(r^{2}\right.$ $=0.86)$ ]. The monaural stop-RT is plotted at $0^{\circ}$ angular separation (originally Figure 2 in Akerboom, ten Hoopen, Olierook, \& van der Schaaf, 1983).

phones). In the latter paradigm, a maximum POA difference of $25 \mathrm{msec}$ was found, whereas in the loudspeaker study we found a POA difference of $12 \mathrm{msec}$ between $180^{\circ}$ alternating and nonalternating conditions. Nevertheless, we have no evidence that the relation between angular separation and POA difference would not also be linear̀ when headphones were used.

In our first attempt to use stop-RTs as a measure of subjective angular separation (Akerboom \& ten Hoopen, 1983), we examined the phenomenon of an ear-alternating signal's being subjectively pushed toward the median sagittal plane by the addition of contralateral signals. Paradoxically, such a "mislocation" improved the intelligibility of the alternating signal. Schubert and Parker (1956) found that the intelligibility of alternated speech, which is at its worst at 3 to 4 alternations/sec (Cherry \& Taylor, 1954), improved when noise was presented to the ear that did not receive the speech signal. Deutsch (1979) reported an analogous effect: The recognition of earalternated melodies improved when the ear that did not receive the melody was filled with a drone (a lower constant-frequency tone).

Akerboom and ten Hoopen (1983) required their listeners to give stop reactions to interaural sequences of $550-\mathrm{Hz}$ signals. The RTs were $20 \mathrm{msec}$ longer than RTs to the monaural control sequences. In the dichotic condi- 
Table 1

Summary of Stop-Reaction Time Experiments That Measured the Difference Between the Interaural and Monaural Perceptual Onset Asynchrony (POA)

\begin{tabular}{|c|c|c|c|}
\hline Study & $\begin{array}{c}\text { Listening } \\
\text { Conditions }\end{array}$ & $\begin{array}{l}\text { Range of SOAs } \\
\text { (in msec) }\end{array}$ & $\begin{array}{l}\text { POA Difference } \\
\text { (in } \mathrm{msec} \text { ) }\end{array}$ \\
\hline $\begin{array}{l}\text { ten Hoopen, Vos, } \\
\text { \& Dispa (1982) }\end{array}$ & Headphones & $125-250$ & 24 \\
\hline $\begin{array}{l}\text { Akerboom, ten Hoopen, } \\
\text { Olierook, \& van der } \\
\text { Schaaf (1983) } \\
\text { Experiments 1-5 }\end{array}$ & Headphones & $40-2,130$ & 25 \\
\hline $\begin{array}{l}\text { Akerboom, ten Hoopen, } \\
\text { Olierook, \& van der } \\
\text { Schaaf }(1983) \\
\text { Experiment } 6\end{array}$ & Loudspeakers & $100-400$ & 12 \\
\hline $\begin{array}{l}\text { Akerboom \& } \\
\text { ten Hoopen (1983) }\end{array}$ & Headphones & $150-450$ & 20 \\
\hline $\begin{array}{l}\text { ten Hoopen \& } \\
\text { Akerboom (1983) } \\
\text { Experiment } 1\end{array}$ & Headphones & $50-600$ & 27 \\
\hline $\begin{array}{l}\text { ten Hoopen \& } \\
\text { Akerboom (1983) } \\
\text { Experiment } 2 \\
\end{array}$ & Headphones & $50-600$ & 25 \\
\hline
\end{tabular}

tion, $350-\mathrm{Hz}$ drones were alternated contralaterally with the $550-\mathrm{Hz}$ signals. The subjects reported that they perceived a single tone alternating between a high and a low pitch, and as expected, this tone made much smaller spatial excursions than the (objective) interaural tone. But, curiously enough, the stop-RTs to the dichotic sequences were precisely the same as those to the monaural control sequences, despite the fact that the subjects perceived a small spatial excursion of the tone. Table 1 summarizes the stop-RT experiments carried out at our laboratory.

In the octave illusion, on the other hand, the single subjective tone appears to make a much larger spatial excursion, although we question whether it is for a full $180^{\circ}$. Therefore, we again applied the stop-RT technique.

\section{EXPERIMENT}

In this experiment, we attempted to measure objectively the amount of subjective angular separation of the high and low tones in the octave illusion. The path of analysis is as follows: The stop-RT difference between an objective nonalternating sequence and an objective earalternating sequence represents the POA difference corresponding to an angular separation of $180^{\circ}$. Given, furthermore, that the relation between the POA difference and the angular separation is linear, the stop-RT yielded by the dichotic octave sequences can be translated into an angular separation. However, two methodological points must be made. First, the subjective tones in the octave illusion alternate not only in subjective location, but also in pitch. Therefore, the stop-RT technique is valid in answering our question only if the pitch alternation per se does not lengthen the stop-RT. In a previous study, we could not establish a significant stop-RT difference between frequency-alternating and monotone sequences (ten Hoopen, van Meurs, \& Akerboom, 1981). This result was corroborated by a subsequent study: Confronted with the method of adjustment, subjects were perfectly able to make a veridical match between the rates of frequency-alternating and monotone sequences (ten Hoopen \& Akerboom, 1982). Therefore, it appears unlikely that the POA of frequency-alternating sequences is longer than that of monotone sequences. Nevertheless, we planned to include frequency-alternating sequences in the present experiment as a control condition.

The second methodological point is crucial: The stopRT technique obviously requires silent intertone intervals. Careful listening taught us that the octave illusion is not harmed by interspersing silent gaps between the successive chords. As Deutsch herself reported: "The durations of the tones themselves do not appear of importance and neither does the time interval between the offset of one tone and the onset of its successor" (Deutsch, 1980, p. 585).

\section{Method}

Subjects. Forty-three students from the University of Leiden ( 17 male and 26 female) were tested to see whether they heard the octave illusion. The subjects were first screened for left- and rightear thresholds at 500 and $750 \mathrm{~Hz}$. The rejection criterion was a loss of $15 \mathrm{~dB}(\mathrm{~A})$ or a difference between the left- and right-ear thresholds of $10 \mathrm{~dB}(\mathrm{~A})$; all of the subjects passed this test with a large margin. They were then required to listen via headphones to a tape on which the dichotic chord (comprising 400 and $800 \mathrm{~Hz}$ pure sine tones) alternated between the ears every $250 \mathrm{msec}$. The audiotape lasted $1 \mathrm{~min}$.

The subjects, who were tested individually, had to report verbally what they heard. In addition, they had to indicate which one of the pictorial representations of the four most frequent percepts (as described by Deutsch, 1975a) corresponded with their sensation. Some subjects wanted to listen to the tape a second or even a third time, which was not encouraged but was allowed.

Twenty-four subjects stated that they heard the octave illusion. Two of them played a musical instrument regularly. The other 22 subjects were invited to participate in the stop-RT experiment. 
One subject refused, and the final sample comprised 6 male and 15 female students, who stated that they were right-handed.

Stimuli and Design. The tones were either 400 or $800 \mathrm{~Hz}$, with durations of $100 \mathrm{msec}$ including a $10-\mathrm{msec}$ rise and a $10-\mathrm{msec}$ fall time. The eight presentation modes were as follows: monaural (either $400-$ or $800-\mathrm{Hz}$ tones were presented to the same ear); interaural (either $400-$ or $800-\mathrm{Hz}$ tones alternated one by one between the ears); frequency-alternating sequences, consisting of alternating 400 - and $800-\mathrm{Hz}$ tones presented to the same ear; frequency- and locationalternating sequences, alternating between 400 and $800 \mathrm{~Hz}$ and at the same time alternating between ears; and dichotic (400- and 800 $\mathrm{Hz}$ tones alternating between the ears and $800-$ and $400-\mathrm{Hz}$ tones alternating contralaterally) (for the sake of reliability, we presented this dichotic presentation mode twice).

In order to equalize the intensity of these different presentation modes, the $400-$ and $800-\mathrm{Hz}$ tones of the dichotic condition were each attenuated by $1.5 \mathrm{~dB}$. The SOA between the tones was 200 , 250 , and $300 \mathrm{msec}$; thus, the corresponding silent intervals were 100,150 , and $200 \mathrm{msec}$. The number of tones in a sequence could be $20,21,22,23,24,25,26$, or 27 .

Thus there were 8 (presentation modes) $\times 3$ (SOAs) $\times 8$ (number of tones) $=192$ different sequences that were blocked with respect to presentation mode and SOA. In each of the 24 blocks the number of tones was randomized. After each tone sequence there was a $2.5-\mathrm{sec}$ silent response interval.

Apparatus and Procedure. The tone sequences were generated on-line by means of Coulbourn Instruments modules controlled by a microcomputer. The subjects were tested individually in a soundattenuated booth (Siemens). The sequences were presented over headphones (AKG Cardan K140S) at a comfortable listening level.

The subjects attended two sessions. In the first session, they were familiarized with the stop-RT task, after which they received 64 different sequences for training (comprising all presentation modes). At the beginning of the second session, which took place 3 or 4 days after the first one, 24 warm-up trials were given. The first session comprised 9 experimental blocks, the second one 15 . The 24 blocks were balanced as far as possible across subjects. During both sessions, each lasting about $60 \mathrm{~min}$, there was a short break of $10 \mathrm{~min}$ halfway through.

The subjects were instructed to react as quickly as possible with a pushbutton response (dominant index finger) when the tone sequence stopped. The stop-RTs, that is, the elapsed time between the end of the last tone and the depressing of the button, were registered by the computer. All apparatus except for the matched headphones and the pushbutton were located outside the booth.

\section{Results and Discussion}

The mean stop-RTs did not differ for the monaural 400 $\mathrm{Hz}$ and monaural $800-\mathrm{Hz}$ sequences, or for the interaural $400-\mathrm{Hz}$ and interaural $800-\mathrm{Hz}$ sequences. Therefore, for further analysis we averaged both the monaural and interaural stop-RTs over both frequency conditions. The mean stop-RTs for the dichotic replications (recall that the subjects did the dichotic blocks twice) did not differ either [ 373 and $370 \mathrm{msec} ; F(1,20)=3.11, p>.09$ ]; therefore, we averaged over the two dichotic replications also.

Mean stop-RTs dependent on SOA and presentation mode (monaural, interaural, frequency-alternating, frequency- and location-alternating, dichotic) are presented in Table 2. Equations of the linear regression lines through the mean stop-RTs are also given.

An analysis of variance (all repeated measures, all factors fixed except subjects) was performed on the stop-RTs. All factors (presentation mode, SOA, number of tones)
Table 2

Mean Stop-Reaction Times (in Milliseconds) Dependent on Presentation Mode and Stimulus Onset Asynchrony (SOA) and Equations of the Linear Regression Lines Through the Mean Stop-RTs

\begin{tabular}{llllll}
$\begin{array}{c}\text { Presentation } \\
\text { Mode }\end{array}$ & 200 & 250 & 300 & Mean & $\begin{array}{c}\text { Equations for } \\
\text { Estimated Mean RTs }\end{array}$ \\
\hline MON & 313 & 372 & 428 & 370 & $\tilde{\mathbf{R T}}=84+1.15$ SOA \\
DICH & 315 & 376 & 425 & 371 & $\tilde{\mathrm{RT}}=97+1.10$ SOA \\
FA & 326 & 383 & 428 & 379 & $\tilde{\mathbf{R T}}=124+1.02$ SOA \\
INT & 331 & 384 & 439 & 384 & $\widetilde{\mathrm{RT}}=115+1.08$ SOA \\
FLA & 338 & 388 & 438 & 388 & $\widetilde{\mathrm{RT}}=138+1.00$ SOA \\
\hline
\end{tabular}
Note $-\overline{R T}=$ reaction time $;$ MON $=$ monaural $; D I C H=$ dichotic; $F A=$ frequency-alternating; $I N T=$ interaural $F L A=$ frequency + locationalternating. The $r^{2} s$ of the regression equations exceeded 0.99 .

yielded significant main effects. The main effect of SOA $[F(2,40)=1640.95, p<.0001]$ is an artifact of the stopRT paradigm: Longer SOAs imply longer POAs, and hence longer stop-RTs. The main effect of number of tones in the sequence was significant $[\mathrm{F}(7,140)=10.55$, $\mathrm{p}<.0001]$, as was the main effect of presentation mode $[F(4,80)=6.89, p<.0001]$. An inspection of the stopRTs dependent on number of tones in the sequence showed a slight decrease in RTs when there were more tones in the sequence.

The pattern of results with regard to the presentation mode was further analyzed by means of the NewmanKeuls procedure (summarized in Table 3 ). The error term was $[1 / \mathrm{nqr} \times \text { MS (presentation mode } \times \text { subjects) }]^{1 / 2}=$ $[(1 /(21 \times 3 \times 8)) \times(4265.34)]^{1 / 2}=2.91$ with $\mathrm{df}=80$.

Although the stop-RT difference, and thus the POA difference, between the interaural and monaural conditions (14 msec) was less than in previous studies (see Table 1), it turned out to be significant. The difference between the interaural and dichotic condition $(13 \mathrm{msec})$ was also significant. An inspection of Table 2 and Figure 2 shows that the mean stop-RTs for the dichotic sequences are almost the same as those for the monaural sequences. Mean stop-RTs dependent on SOA and as a function of monaural, dichotic, and interaural presentation modes are plotted in Figure 2. Three linear regression lines were fitted, one for each presentation mode. The slopes of these

Table 3

Summary of the Newman-Keuls Test on the Differences in Stop-Reaction Time (in Milliseconds) Between Presentation Modes

\begin{tabular}{lrrrrrr}
\hline & & MON & DICH & \multicolumn{1}{c}{ FA } & \multicolumn{1}{c}{ INT } & \multicolumn{1}{c}{ FLA } \\
\hline & & 370.83 & 371.92 & 379.10 & 384.43 & 388.31 \\
MON & 370.83 & & 1.09 & $\mathbf{8 . 2 7}$ & $\mathbf{1 3 . 6 0}$ & $\mathbf{1 7 . 4 8}$ \\
DICH & 371.92 & & & 7.18 & $\mathbf{1 2 . 5 1}$ & $\mathbf{1 6 . 3 9}$ \\
FA & 379.10 & & & & 5.33 & 9.21 \\
INT & 384.43 & & & & & 3.88 \\
FLA & 388.31 & & & & & \\
\hline
\end{tabular}

Note-MON = monaural; $D I C H=$ dichotic; $F A=$ frequencyalternating; $I N T=$ interaural; $F L A=$ frequency + location-alternating. The error term was $[1 / \text { ing } \times \text { MS (presentation mode } \times \text { subjects) }]^{1 / 2}=$ $[(1 /(21 \times 3 \times 8)) \times(4265.34)]^{1 / 2}=2.91$ with $d f=80$. The differences printed in boldface were significant at .01 . 


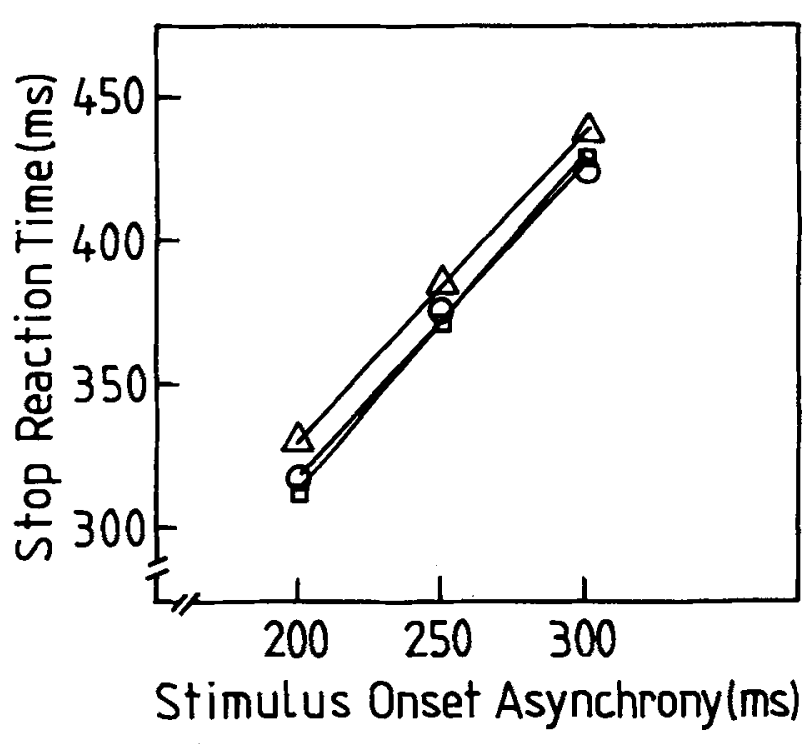

Figure 2. Mean stop-reaction times as a function of stimulus onset asynchrony and presentation mode (interaural $=\triangle \longrightarrow \Delta$, monaural $=[]-\square$, and dichotic $=O-O$ ). The linear regression lines are inserted (their equations are given in Table 2).

lines are nearly equal and the regression lines for the dichotic and monaural condition cover each other, whereas the regression line through the interaural mean stop-RTs is elevated.

Furthermore, the frequency- and location-alternating condition differed significantly from the monaural condition. The stop-RTs for the interaural and the frequencyand location-alternating condition did not differ (384 and $388 \mathrm{msec}$, respectively). This indicates that the apparent tempo of the combined alternation was determined solely by the location-alternating component.

That the stop-RTs to the dichotic sequences, although perceived as alternating between pitches and locations, did not differ from the stop-RTs to the monaural sequences implies that there is no POA-stretching in the octave illusion. Thus we have to conclude that the interaural tempo illusion occurs only when sounds alternate objectively between the ears. This conviction is corroborated by the data of the frequency-and location-alternating condition, because this condition is the objective counterpart of the octave-illusion percept and in fact does yield a POAstretching of $17 \mathrm{msec}$.

In summary, it can be concluded that although the sound percepts in the dichotic condition alternate in illusory fashion between the ears, these-percepts are not spaced farther apart in subjective time. This fact reveals something about the order of the auditory mechanisms that evoke the interaural tempo illusion and the octave illusion. Because the output of the "what-where" mechanism (giving rise to the octave illusion) is not transformed in time by the interaural tempo processor, the latter probably operates at a lower auditory stage than the former. Further research should establish the levels in the auditory system at which auditory illusions arise.

\section{REFERENCES}

AKerboom, S., \& TEN HoOpen, G. (1983). The effect of a contralateral drone on the perceptual onset asynchrony of interaural tone sequences. Perception \& Psychophysics, 33, 571-574.

AKerboom, S, ten HoOpen, G., Ollerook, P., \& VAN der SCHAAF, T. (1983). Auditory spatial alternation transforms auditory time. Joumal of Experimental Psychology: Human Perception \& Performance, 9, 882-897.

Axelrod, S., \& PowazeK, M. (1972). Dependence of apparent rate of alternating clicks on azimuthal separation between sources. Psychonomic Science, 26, 217-218.

Bregman, A. S. (1978). The formation of auditory streams. In J. Requin (Ed.), Attention and Performance VI. Hillsdale, NJ: Erlbaum.

Broadbent, D. E. (1971). Decision and stress. London: Academic Press.

CherRy, E. C., \& TAYLOR, W. K. (1954). Some further experiments upon the recognition of speech, with one and with two ears. Journal of the Acoustical Society of America, 26, 554-559.

Deutsch, D. (1974). An auditory illusion. Journal of the Acoustical Society of America, 55, 518-519.

Deutsch, D. (1975a). Musical illusions. Scientific American, 223, 94-104.

DEUTSCH, D. (1975b). Two channel listening to musical scales. Journal of the Acoustical Society of America, 57, 1156-1160.

DEUTSCH, D. (1979). Binaural integration of melodic patterns. Perception \& Psychophysics, 25, 399-405.

DEUTSCH, D. (1980). The octave illusion and the what-where connection. In R. S. Nickerson (Ed.), Attention and performance VIII. Hillsdale, NJ: Erlbaum.

DeuTsCH, D. (1982). Grouping mechanisms in music. In D. Deutsch (Ed.), The psychology of music. New York: Academic Press.

DeUTSCH, D., \& Roll, P. L. (1976). Separate "what" and "where" decision mechanisms in processing a dichotic tonal sequence. Journal of Experimental Psychology: Human Perception \& Performance, 2, 23-29.

Moray, N. (1969). Attention: Selective processes in vision and hearing. London: Hutchinson Educational.

Schubert, E. D., \& PARKer, C. D. (1956). Addition to Cherry's findings on switching speech between the two ears. Joumal of the Acoustical Society of America, 27, 792-794.

TEN HOOPEN, G. AKERBoom, S. (1982). The perceived tempi of coherent and streaming tone sequences: II. Perception \& Psychophysics, 32, $481-485$.

TEN HOOPEN, G., \& AKERBOOM, S. (1983). The subjective tempo difference between interaural and monaural sequences as a function of sequence length. Perception \& Psychophysics, 34, 465-469.

ten Hoopen, G., van Meurs, G., \& AKerboom, S. (1981). The perceived tempi of coherent and streaming tone sequences. Perception \& Psychophysics, 31, 256-260.

TEN HOOPEN, G., Vos, J., \& DISPA, J. (1982). Interaural and monaural clicks and clocks: Tempo difference versus attention switching. Journal of Experimental Psychology: Human Perception \& Performance, 8 , $422-434$

ZWICKER, T. (1984). Experimente zur dichotischen Oktav-Täuschung. Acustica, 55, 128-136.

\section{NOTE}

1. It should be stressed that it is not only the "location" that differs between the messages in the dichotic simulation of the cocktail party phenomenon, but "location + meaning." These attributes are necessarily confounded; otherwise the experimenter could not check whether the listener is shadowing the primary or secondary message. Hence, when comparing the selective powers of attributes it is justifiable to compare "location + meaning" with "meaning," and it is not justifiable to interpret the shadowing results as a difference in selective power between location alone (the precategorical attribute) and meaning (the postcategorical attribute)

(Manuscript received November 12, 1984; revision accepted for publication August 30, 1985.) 